\title{
UN “EJÉRCITO DE RESERVA DE DELINCUENTES”: LA CRIMINALIZACIÓN Y EL CASTIGO ECONÓMICO DE LOS INMIGRANTES EN ESPAÑA ${ }^{\mathrm{a}}$
}

\author{
Kitty Calavita ${ }^{\mathrm{b}}$ \\ Universidad de California
}

\section{RESUMEN}

Este artículo estudia el papel que juegan los inmigrantes irregulares en la política económica española, su criminalización y las distintas formas de castigo relacionadas con la condición de inmigrante irregular. Basado en datos secundarios, documentos oficiales e investigaciones de campo, argumento en este trabajo que las Leyes de Extranjería españolas se centran principalmente en definir los niveles de exclusión /inclusión socio-económica. La consecuencia de estas previsiones legales es la marginación de los inmigrantes, relegándolos a la economía sumergida como una especie de sanción económica derivada precisamente de su condición de inmigrante irregular. Finalmente, esta sanción y la marginación económica contribuyen a reforzar la 'flexibilidad' que los inmigrantes suministran a la economía post-Fordista, y por la que son tolerados a regañadientes.

\section{ABSTRACT}

This article explores the role of 'irregular' immigrants in the political economy of Spain, their related criminalization and the forms of punishment that attach to their illegal status. Based on secondary data, government documents and field research, I argue that Spanish immigration laws primarily focus on defining levels of social and economic inclusion/exclusion, and that they have the consequence of marginalizing immigrants and consigning them to the extensive underground economy, as a kind of economic sanction for their illegal status. Finally, it is this punishment and the economic marginalization it helps constitute that shore up the 'flexibility' that immigrants provide the post-Fordist economy and for which they are reluctantly tolerated.

Palabras clave: inmigración laboral, castigo y marginación, exclusión social y económica, Ley de Extranjería española.

\section{Introducción}

Hace poco, a una mujer negra con pasaporte británico se le denegó el embarque en un avión de la compañía Air France porque los empleados de la aerolínea no creyeron que ella fuera realmente ciudadana británica. Por otro lado, un escritor estadounidense que vive en España desde hace 25 años es sistemáticamente corregido cuando se refiere a sí mismo como inmigrante. Se le dice de forma educada pero firme que es 'extranjero' pero no 'inmigrante'. Inmigrantes son los trabajadores procedentes de países del Tercer Mundo que trabajan en el campo o barren las calles, aún cuando ellos, a diferencia del estadounidense, vengan a España sólo para unos meses o incluso no tengan ninguna intención de "inmigrar".

\footnotetext{
${ }^{a}$ Traducción de Daniel Wagman y Elisa García Espana sobre un artículo publicado originalmente en Punishment and Society (2003), ol 5: 399-413.

${ }^{\mathrm{b}} \mathrm{La}$ investigación sobre la que se basa este artículo ha sido financiada por la 'Law and Social Science Program' de la 'National Science Foundation', con número de subvención SES-0004218.

Revista de Española de Investigación Criminólogica

REIC NI-03-04 http://www.criminologia.net/revista

ISSN 1696-9219 
Estas anécdotas hablan de inmigrantes como "'atopos', sin lugar, desplazados" (Bourdieu, 1991:9); una "figura.....alrededor de la cual se condensa pura alteridad" (Brubaker, 1992:47). En la segunda anécdota, la definición de inmigrante incluye la referencia a la marginación. Los extranjeros procedentes de países del Primer Mundo no son conocidos coloquialmente en España como inmigrantes, ya que este término se reserva para aquellos que son realmente 'los otros' ('outsiders'), y no a los que técnicamente han inmigrado. En el primer supuesto expuesto anteriormente se observa también que quienes no son de facto extranjeros, sino ciudadanos de pleno derecho, pueden ser 'los otros' ('outsiders'), esto es inmigrantes de facto, al igual que los que cruzan clandestinamente las fronteras.

En este artículo se analiza el rol de los inmigrantes/outsiders en la política económica de una sociedad capitalista tardía, su criminalización y las formas de castigo que se imponen a su ambigua condición de delincuente. España se ha convertido recientemente en un país receptor de inmigración a gran escala. Este hecho hace que sea interesante estudiar de qué forma se ponen de manifiesto las contradicciones asociadas a la política migratoria. El argumento que se mantiene en estas líneas es que más que controlar el número de inmigrantes que entran en España, la Ley de Extranjería se centra principalmente en definir los niveles de inclusión/exclusión social y económica. Además, considero que esas políticas están estructuradas de tal manera que una de las consecuencias predecibles es la marginación de los inmigrantes procedentes del Tercer Mundo, relegándolos a la economía sumergida como una forma de castigo encubierto por su condición administrativa de ilegalidad.

No es particularmente original afirmar que los trabajadores indocumentados suministran a las economías capitalistas una fuente de mano de obra que carece de poder para exigir concesiones a los empleadores (Castles y Kosack, 1973; Bustamante, 1978; Calavita, 1992; Cornelius et al., 1994). Lo que sí quiero analizar en cambio es cómo esta marginación es sistemáticamente construida por la Ley de Extranjería. Utilizo la Ley de Extranjería 4/2000 (Boletín Oficial del Estado, 2000 a) para mostrar hasta qué punto esa ilegalidad ha sido institucionalizada. Esta ley previó que los inmigrantes irregulares ya no serían considerados expulsables, sino que podían ser miembros permanentes en la sociedad, creándose así un grupo de trabajadores que son sistemáticamente privados de los derechos básicos propios de una sociedad democrática liberal, como una forma de castigo por su situación de irregulares. De esta manera, los inmigrantes irregulares se encontraban en una especie de limbo legal, un estatus ambiguo que recoge perfectamente las contradicciones de su rol en la política económica. En menos de un año, esta ley fue reformada por la Ley Orgánica 8/2000 (Boletín oficial del Estado, 2000 b). Esta ley se caracteriza por ser más restrictiva, dando a la policía de fronteras competencias para expulsar a los inmigrantes sin papeles, y por denegar a este colectivo el derecho de sindicación y huelga.

Simon (1993) y Young (1996) han tratado elocuentemente la idea de 'el otro como el que está fuera de la ley'. Young considera la exclusión de estos 'otros' como un esfuerzo contraproductivo en la construcción de la comunidad. Simon mantiene que en las sociedades post-industriales del siglo XXI, el concepto de "peligroso social" y la criminalización de las clases bajas desempleadas vuelven a ser útil para comprender el sistema de justicia penal. Él apunta a que la población de parados crónicos con rasgos raciales diferenciados ha sido criminalizada en parte como una forma de ignorar su marginación económica. Para el supuesto que aquí tratamos, el exogrupo de inmigrantes es percibido como un grupo al margen de la ley (outlaw), pero no viceversa, y que es Revista de Española de Investigación Criminólogica 
precisamente su estatus de trabajadores (y no de desempleados) lo que les conduce a la marginación. Es decir, el castigo que un inmigrante recibe por su situación administrativa de ilegalidad es denegarles plenos derechos económicos. Esta sanción y su marginación económica contribuye a reforzar la 'flexibilidad' que los inmigrantes suministran a la economía post-Fordista.

En el siguiente apartado comento brevemente los aspectos coincidentes entre los conceptos de inmigrante irregular y delincuente, y las reflexiones que se alcanzan estudiando los paralelismos existentes entre los castigos económicos y los castigos penales que respectivamente recaen sobre ambos. Seguidamente, muestro una visión de la inmigración en España y de la política migratoria española. El resto de este artículo se centra en la manera en que las políticas sancionan y marginan simultáneamente a los inmigrantes, construyendo y reconstruyendo su condición de 'otros'.

\section{El desviado y el extraño}

El sociólogo Georg Simmel (1950) en su clásica obra 'El extraño' sugería que los inmigrantes son el prototipo de extraño, físicamente presentes en la comunidad, pero sin formar parte de ella. Debido a que son literalmente 'de fuera', los inmigrantes, como todos los extraños, no son percibidos como miembros plenos de, ni participantes en, la vida social y cultural de la comunidad. Además, esta no-pertenencia, esta cualidad de ser foráneo, les dota de un aura de peligro potencial. Como han comentado Sayad (1996) y Melossi (1999, 2000a: 152), el inmigrante afronta un doble riesgo.

El extraño, siendo de entrada culpable por su diferencia o rareza... será un blanco fácil sobre el que recaiga todo tipo de sospechas sobre su participación en actos criminales y desviados. Si un extraño comete alguno de estos actos... el círculo vicioso será perfecto y el extraño será encontrado doblemente culpable, por su rareza y por su desviación. ... (Melossi, 2000a: 152).

Mientras las fuerzas de la globalización van uniendo a los países del Primer Mundo en una misma comunidad económica y cultural, la categoría de inmigrante / extraño se reserva exclusivamente para los 'otros' extranjeros procedentes del llamado Tercer Mundo. Y, como veremos en el caso de España, un porcentaje importante de estos inmigrantes están definidos como ilegales. No importa que no hayan cometido ninguna infracción penal, la condición de inmigrantes irregulares les marca como personas 'fuera de la ley'. Y en cierto modo los inmigrantes irregulares en España, como en otros lugares del mundo, no solo son extraños, sino también, y como consecuencia de su estatus ilegal, son por definición 'desviados' y 'la tautología [es] perfecta...' (“'the viciousness of the circle [is] perfect..."'). De Lucas llama a los inmigrantes el 'ejército de reserva de delincuentes' (1994: 84), un término que capta perfectamente lo que quiero decir acerca de que el estatus de criminalizado y marginado del inmigrante ilegal lo convierte en un trabajador ideal (flexible) para la economía post Fordista actual.

No sorprende que, en esa situación de sospecha hacia los inmigrantes, éstos estén sobre-representados en las cárceles españolas (1). En 1990, al comienzo de la actual ola de inmigración hacia España, los extranjeros ya constituían el 15\% del total de presos (Sánchez Yllera, 1990: 65). En 2001 la cifra aumentó hasta aproximadamente el 20\%, a pesar de que las personas nacidas en el extranjero que residían en el país tan solo eran un

Revista de Española de Investigación Criminólogica 
2\% o 3\% de la población general (Ministerio del Interior, 2001) (2). Sánchez Yllera (1990: 68) indica que, debido a que la legislación sobre extranjería impide a los que han sido condenados por delitos graves obtener un permiso de residencia, los inmigrantes que salen de la cárcel están condenados a llevar una vida de ilegalidad marginada. Lejos de 'integrar' en la sociedad española a los inmigrantes que han cumplido una pena de prisión en el país que es el objetivo explícito de la legislación de extranjería y del sistema penal - Sánchez Yllera (1990) argumenta que para los inmigrantes la encarcelación y su posterior situación penalizada constituye una 'doble condena'.

Pero quisiera llegar aún más lejos. Para empezar, los inmigrantes en España están castigados por su condición administrativa de ilegalidad aun sin haber sido encarcelados, es decir, la segunda parte de la 'doble condena' que comenta Sánchez Yllera (1990). Más allá de la sospecha genérica que todo 'extraño' provoca, como Simmel y otros han comentado, estos inmigrantes están aún más marginados por las políticas que aseguran la contingencia y la precariedad de su estatus legal, sufriendo penalizaciones económicas sustanciosas por su situación de ilegalidad, lo que ocurre con una regularidad predecible.

Ali Behdad dice que la inmigración en los Estados Unidos es 'tanto un mecanismo necesario de control social en la formación del aparato del Estado, como una contribución cultural esencial para la formación de la identidad nacional' (1997: 155). Aunque la inmigración cumple ambas funciones, política y cultural, en muchos contextos nacionales, Behdad (1997: 156) sostiene que dichas funciones son particularmente importantes en los Estados Unidos, donde el 'estado-nación' históricamente ha sido un 'concepto ambiguo'. En este contexto, "la figura del "extranjero" contiene un significado diferencial a través del cual la nación se define a sí misma como una comunidad con autonomía, [y] las previsiones legales, jurídicas y administrativas, sobre inmigración fortalecen la soberanía colectiva del Estado moderno'. Pero, si el poder disciplinario del Estado para regular la inmigración (1997: 156) es clave para la formación de la legitimidad del estado-nación y la identidad cultural, es también central para las relaciones económicas. En ambos casos la cuestión no es tanto el poder del Estado de controlar la inmigración y mantener las fronteras (un poder que en todo caso se ha mostrado efímero), como su capacidad para controlar y marginar a los inmigrantes, definiéndolos como 'extraños de fuera', aumentando así su potencial aportación a las relaciones económicas capitalistas.

El siguiente epígrafe aporta un resumen de este proceso de ilegalización de los inmigrantes en España, las sanciones y marginación económica que les acompañan, y la 'flexibilidad' que estos castigos económicos aportan.

\section{Un breve resumen sobre la inmigración en España}

España se ha convertido recientemente en un país receptor de inmigración a gran escala. El número de extranjeros con permiso de residencia aumentó de un poco más de 183.000 en 1980 a más de 1.200 .000 en 2002 (Ministerio del Interior, citado en Generalitat de Catalunya, 2002; $A B C$, Abril 17, 2002). Las estimaciones sobre el número de extranjeros que viven en España sin permiso para ello oscilan entre 200.000 y 300.000 (Amnesty International, 2002). Es difícil estimar el número de 'irregulares' porque, por una parte, la propia condición de indocumentados los hace oficial y oficiosamente invisibles, pero también porque no son poblaciones distintas. No sólo los residentes legales pierden su estatus legal cuando su permiso caduca, como veremos más adelante, sino que hay

Revista de Española de Investigación Criminólogica 
campañas periódicas de regularización que reducen temporalmente, y en ocasiones de forma drástica, el número de residentes ilegales.

Aproximadamente el $51 \%$ de los extranjeros con residencia legal en España proceden de otros países europeos. Éstos, por ser ciudadanos de países de la Unión Europea (UE), tienen los mismos derechos que los españoles para vivir y trabajar en España, e incluso pueden votar en las elecciones municipales (Comisión Interministerial de Extranjería, 1995: 24, 22). Indicativo de su estatus especial en comparación con otros extranjeros es el hecho de que los derechos de los ciudadanos de los países miembros de la UE en España se recogen principalmente en las normas y tratados de la UE, en lugar de encontrarse regulados en la Ley de Extranjería.

El mayor número de extranjeros en España procede de Marruecos, con aproximadamente 235.000 residentes legales. El continente africano aporta el $27,4 \%$ de los residentes legales, América el 27\% y Asia el 8\% (Ministerio del Interior, 2001: 28). Estas cifras sólo se refieren a los extranjeros con residencia legal. Un experto en inmigración estima que aproximadamente el $40 \%$ de todos los extranjeros en España -tanto legales como los sin papeles- proviene de los países desarrollados, y el otro $60 \%$ vienen del llamado Tercer Mundo (entrevista con John Casey, Universidad Autónoma de Barcelona, 1997).

La mayoría de los inmigrantes del Tercer Mundo trabajan en la agricultura, la construcción o el sector servicios, y muchos de ellos lo hacen en la economía sumergida. En 1987, un estudio sobre inmigrantes procedentes de Marruecos, África Central y Filipinas descubrió que el $80 \%$ de los inmigrantes entrevistados habían obtenido su primer empleo en la economía sumergida, y que este tipo de trabajo se prolongaba de tres a cuatro años (Sole, 1995: 28). Otros estudios sobre marroquíes en Madrid (González-Anleo, 1993; Pumares, 1996), trabajadores africanos en la agricultura en Cataluña (Jabardo, 1995) y Andalucía (Roquero, 1996), africanos y latinoamericanos en Barcelona (Valls et al., 1995) y otro inmigrantes del Tercer Mundo (Ramírez Goicoechea, 1996) llegan a la misma conclusión. Estos inmigrantes, sean temporalmente legales o hayan estado un tiempo indocumentados, trabajan en los puestos de trabajo más duros, peor remunerados, y con mucha provisionalidad. Algunos llegan a trabajar en siete empleos diferentes en un solo año (Pumares, 1996: 88).

Los sueldos de los inmigrantes varían, dependiendo del sector de la economía y la región del país. Pero una cosa es constante: Reciben menos retribución que un trabajador español en cada tipo de trabajo y en cada sector de la economía. Un estudio realizado por el Gobierno de Cataluña encontró que la remuneración por hora para un inmigrante era del $21 \%$ menos que la que recibía un autóctono por un trabajo similar en la agricultura, el 18\% menos en la construcción, el 40\% menos en industria, y el 50\% menos en el sector servicios, que es el sector en el que mayoritariamente se concentran los inmigrantes (Generalitat de Cataluña, 1995: 63). El antiguo Director General de Migraciones estima que el 25\% de los inmigrantes reciben un sueldo inferior al salario mínimo (citado en Malgesini, 1994: 16-17). Cáritas, una organización católica de apoyo a los inmigrantes, estima que el $78 \%$ de los inmigrantes en España tienen un ingreso mensual de menos de 50.000 pesetas -360 dólares- (citado en Lucas, 1996:34).

Revista de Española de Investigación Criminólogica 


\section{La política migratoria y la Ley de Extranjería españolas}

Antes de 1985 España no tenía una verdadera política migratoria, ni una legislación global en materia de extranjería. En junio de 1985 España entró en la Comunidad Europea y ese mismo mes cinco países miembros (Bélgica, Francia, Alemania, Luxemburgo y Holanda) firmaron el acuerdo Schengen, que fue el comienzo de la desaparición de sus fronteras interiores. En el contexto de una Europa más amplia, el parlamento español aprobó la 'Ley Orgánica sobre Derechos y Libertades de los Extranjeros en España'. La ley entró en vigor el 1 de julio de 1985, sólo unos días después de que España firmara el tratado de adhesión a la Comunidad Europea (Boletín Oficial del Estado, 1985: 20824-9).

Mercedes Jabardo, una antropóloga que ha realizado estudios sobre los trabajadores agrícolas africanos en Cataluña, dijo, en relación con la ley de extranjería de 1985, que 'La nueva legislación [LOE]... genera irregularidad entre la gran mayoría de la comunidad inmigrante... En otras palabras, la ley crea la categoría de inmigrantes legales y... genera la categoría de "ilegal" (1995: 86-7). Obviamente es cierto que antes de la LOE, como no había ninguna ley de extranjería en España, no había inmigrantes 'ilegales'. Pero la nueva ley produjo situaciones de 'irregularidad' de una forma mucho más sutil, ya que el desplazamiento hacia la ilegalidad era provocada precisamente por la ley de extranjería. La construcción de esta ilegalidad a través de la ley es producto de varios factores, siendo los más importante la contingencia en la concesión del estatus legal y la naturaleza provisional de dicho estatus.

En España rige el ius sanguinis, y no el ius solis, en la adquisición de la nacionalidad. Si una persona no tiene 'sangre' española es muy difícil obtener todos los derechos de ciudadanía española. Los niños nacidos en España de padres que no son nacionales españoles no adquieren automáticamente la nacionalidad, e incluso pueden estar ilegalmente en el país dependiendo de la situación administrativa de sus padres. Los extranjeros que se casan con ciudadanos españoles no lo tienen mejor, ya que desde 1996 los inmigrantes indocumentados casados con españoles tienen que esperar tres años para poder conseguir la residencia legal.

Hay pocas vías adicionales para conseguir el estatus de residente permanente. En general, antes de 1996 hacía falta tener 10 años de residencia continuada antes de poder solicitar la residencia permanente. Desde la reforma de 1996 (Real Decreto 155/1996, Ministerio del Interior, 1996), el tiempo de espera se ha reducido a seis años. Sin embargo, muy pocos inmigrantes consiguen este permiso de residencia permanente por lo difícil que resulta mantener durante seis años sin interrupción el permiso de residencia y trabajo (entrevista con Miguel Pajares, Director de Servicios de Inmigración, CC.OO, Barcelona).

La naturaleza provisional de la situación de legalidad se aprecia en la inestabilidad inherente al programa que en teoría estaba diseñado para facilitar la integración de los inmigrantes -la 'regularización' de los inmigrantes ilegales. La primera regularización surgió con la entrada en vigor de la LOE en 1985, seguido por un programa más amplio en 1991, y otro más reducido en 1996. Aunque técnicamente no son programas de regularización, el sistema de cupos de trabajadores temporales desarrollado en 1993 para los sectores de la agricultura, la construcción y el servicio domestico, también se ha convertido en una vía de regularización para inmigrantes que ya vivían en España. El cupo de 1999 fue de 30.000 plazas de trabajadores temporales en esos tres sectores, y la mayoría se concedieron a inmigrantes sin papeles que ya estaban en el país.

Revista de Española de Investigación Criminólogica 
Estos programas de regularización son específica y exclusivamente para trabajadores extranjeros que tengan un contrato de trabajo o lo hayan tenido recientemente. Los problemas que tienen los inmigrantes ilegales para cumplir este requisito, debido a que generalmente trabajan en la economía sumergida, son grandes no sólo porque en la economía sumergida - casi por definición - no se realizan contratos formales de trabajo, sino porque algunos empleadores prefieren claramente trabajadores sin papeles, y la vulnerabilidad que este estatus implica. Estudios cualitativos basados en entrevistas en profundidad con inmigrantes sudamericanos y africanos en Barcelona y Madrid revelan que no es infrecuente que los inmigrantes sean despedidos por sus empleadores cuando intentan legalizar su situación (Valls et al., 1995; Pumares, 1996). Un hombre de Guinea Ecuatorial, que perdió su empleo cuando solicitó a su jefe ayuda para regularizar su situación administrativa en España, explica que 'aquí, cuando se da un empleo a un inmigrante, prefieren que trabaje en condiciones que no son legítimas, y preferentemente en situación ilegal, así pueden pagar lo que quieren y las condiciones son más favorables para los empleadores'. Otro inmigrante de Gambia dijo simplemente que 'si trabajas en el campo y le pides a tu jefe un contrato, ese día pierdes tu empleo' (citado en Valls et al., 1995: 125, 127).

Los inmigrantes que consiguen regularizar su situación tienen problemas para mantener su estatus legal, ya que las renovaciones anuales dependen de tener un contrato formal de trabajo. Algunos inmigrantes no consiguen renovar su permiso, al haber finalizado el contrato que le permitió su regularización inicial. Otros descubren que el contrato prometido que permitió su regularización nunca se materializó. Por lo visto no es infrecuente que los 'pre-contratos' no se formalicen en los casos en los que el empleador no quiere pagar la seguridad social o cumplir con otras formalidades, dejando al inmigrante recién legalizado trabajar sin contrato, e imposibilitando así la renovación de su permiso al final del año (Izquierdo, 1996: 73; Pumares, 1996: 87-9).

El sistema de concesión y renovación de los permisos de trabajo es similar y paralelo a los programas de regularización. Los residentes extranjeros que han sido legalizados deben conseguir un pre-contrato de trabajo de un empleador, para poder solicitar un permiso de trabajo. Los permisos de trabajo son temporales, la gran mayoría por un año, o incluso por menos tiempo. Y al igual que en el caso de la regularización, conseguir un permiso de trabajo, y renovarlo cuando termina, requiere tener un contrato formal de trabajo. Esto es un obstáculo casi imposible de superar para la mayoría de los inmigrantes procedentes de países del Tercer Mundo. Teniendo en cuenta la dificultad para conseguir un permiso de trabajo, no es sorprendente que la mayoría de los inmigrantes del Tercer Mundo trabajen ilegalmente, sin el permiso correspondiente. En 1996, con una población de trabajadores inmigrantes de aproximadamente 300.000, fueron emitidos menos de 90.000 permisos (Ministerio de Trabajo y Asuntos Sociales, 1997: 201). Unos estudios independientes de asociaciones de inmigrantes del Tercer Mundo sobre censos de población de inmigrantes alcanzan como conclusión que, entre los inmigrantes, existe una preponderancia de 'irregulares'. Según Izquierdo 'entre marroquíes y argelinos la irregularidad es la norma, no la excepción' (1996: 24). Cuatro de cada cinco africanos que trabajan en el sector agrario en Cataluña son ilegales (Jabardo, 1995). Un experto en inmigración, enumerando las barreras existentes para conseguir un permiso de residencia y trabajo, afirma que la legislación española produce una 'irregularidad institucionalizada' (Santos, 1993: 111).

Revista de Española de Investigación Criminólogica 


\section{Reestructuración económica y legalidad contingente}

La inmigración hacia España se produce en una época de importante reestructuración post-Fordista. Un número considerable de expertos (Piore y Sabel, 1984; Lipietz, 1985, 1987; Sayer y Walker, 1992) han hablando de una amplia 'crisis del Fordismo', que afecta a muchas sociedades capitalistas avanzadas. Según su argumentación, desde la Segunda Guerra Mundial hasta medianos de los años setenta las economías capitalistas avanzadas operaban con los principios de producción en serie de productos estandarizados para el consumo de masas, con mecanismos internos de ascenso en los puestos de trabajo en sectores verticalmente integrados, y apoyado por un sistema gubernamental de mantenimiento de ingresos y seguridad social. Como explica Lipiets (1985: 135), el Fordismo en los Estados Unidos y en la mayoría de los países de Europa Occidental (España en la época franquista siguió un camino algo diferente) se basaba en una relación directa entre niveles de beneficio, salarios y seguridad social. Pero en los años setenta, según esta misma interpretación, los problemas del equilibrado de línea (como resultado de escaseces y excesos de producción), la resistencia obrera y, en general, una rígida estructura de producción, hicieron peligrar los beneficios, y el sistema empezó entonces a desmoronarse. Así, cuando la economía de España, tras el franquismo, empieza a despegar en los años ochenta, lo hizo dentro del contexto de una economía capitalista global, que ya estaba movilizándose para afrontar la llamada crisis de Fordismo.

Una de las soluciones encontradas para esta crisis ha sido la de reducir los costes laborales a través de la eliminación de puestos de trabajo y/o exportando trabajo hacia países en vías de desarrollo, aprovechado así no sólo los reducidos costes laborales en el extranjero, sino también una mano de obra local cada vez más insegura. Otra medida para reducir el coste en este periodo de reestructuración ha sido la de emplear trabajadores para tareas específicas o durante determinadas temporadas, prescindiendo de ellos cuando la demanda de mano de obra se reduce. Aproximadamente el 30\% de la mano de obra en los EE.UU ocupa puestos 'precarios', con contratos a tiempo parcial o de corta duración, con los que no se acumula antigüedad laboral ni se disfruta de muchos beneficios (Ingwerson, 1993: 9). El trabajo precario es aún más común en España. Según un estudio, el 75\% de todas los contratos nuevos en 1996 fueron de tres o menos meses de duración. El 50\% de dichos contratos tienen una duración de un mes (Mazuelos, 1997: 17). En otro estudio (Calavita, 1998), he argumentado que el aumento del trabajo precario y el abaratamiento de los sueldos es consistente con la existencia de altos niveles de inmigración ilegal. Una gran cantidad inmigrantes con trabajos 'precarios' - tanto irregulares como legales - puede ser adecuado para las economías reestructuradas de finales del siglo XX, proliferando así el trabajo precario y mal pagado. Como dijo una vez un antiguo Ministro de Trabajo, los inmigrantes sin papeles 'trabajan duro y con miedo' (Marshall, 1978: 169).

Pugliese describe el contexto económico y la participación de la mano de obra inmigrante en ella:

'La crisis del modelo de producción Fordista tiene graves consecuencias para la demanda laboral y, consecuentemente, para la estructura ocupacional... Muy importante para la ubicación ocupacional del inmigrante es la reducción del volumen de empleos regulares, estables y no-provisionales... El empleo precario suele ser característico de nuevos puestos de trabajo en el sector industrial y, sobre todo, en el sector servicios. La precariedad en la mano de obra es una de las tendencias más importantes del mercado

Revista de Española de Investigación Criminólogica 
laboral... Esto explica por qué los inmigrantes se ubican (incluso)... en regiones donde hay altos niveles de paro'(1995: 61-2) (3).

Algunos políticos españoles afirman que la economía depende de la mano de obra del Tercer Mundo no sólo porque aporta trabajadores (con altos niveles de paro, este argumento sería difícilmente sostenible), sino también porque debilita la rigidez y aumenta la competitividad de la economía global post Fordista. El antiguo Director General de Migraciones ha indicado que la existencia de altos niveles de paro no necesariamente es contradictorio con la demanda de mano de obra inmigrante, añadiendo que el mercado laboral español 'contiene ciertas rigideces' que pueden ser aliviadas precisamente por mano de obra procedente del Tercer Mundo (citado en Mercado, 1992: 27). En 1994, el Plan de integración social de los inmigrantes del Consejo de Ministros (Ministerio de Asuntos Sociales, 1995: 29) concluyó que las 'rigideces en el mercado laboral, las resistencias (de la población autóctona) a la movilización geográfica para el aprovechamiento de oportunidades laborales y los altos niveles de protección social' hace que sea necesario la mano de obra extranjera, a pesar de los altos niveles de paro entre la población autóctona. Los inmigrantes del Tercer Mundo, cuya desesperación y vulnerabilidad han sido reforzadas por las leyes (según Santos 'institucionaliza la ilegalidad'), son ideales para esas funciones.

\section{La suspensión de la expulsión: una decriminalización parcial}

En 2000 una nueva ley de inmigración (Ministerio de Asuntos Sociales, 1995: 29) parecía formalizar esta institucionalización de la ilegalidad. Esta ley establecía que mientras la situación de irregularidad impedía la plena participación en la comunidad, ello no era base legal suficiente para proceder a la expulsión. En otras palabras, la ley 'descriminalizaba' parcialmente a los inmigrantes sin papeles, consintiendo oficialmente su presencia en el país. Lo más sorprendente es que esta ley establecía inconscientemente que la estancia en el país de un extranjero sin papeles era ilegal y al mismo tiempo y en realidad no lo era.

El impacto de esta ley, que fue reformada rápidamente por el partido de centroderecha que en ese momento gobernaba en España y presidía la Comunidad Europea, no debe ser exagerado. En primer lugar, porque los inmigrantes en España, incluido los que tienen incoados un procedimiento de expulsión, raras veces son expulsados. Debido a los escasos recursos por parte de la Administración para ejecutar las expulsiones incoadas y las elevadas tarifas aéreas hacía algunos destinos como Latinoamérica o Asia, la amenaza de la expulsión ha sido siempre más simbólica que real. Así, mientras el número de expulsiones ordenadas anualmente antes de la entrada en vigor de esta ley era de unas 15.000, en el año 1996 se ejecutaron menos de 5.000 (Comunicación personal con Dirección General de la Policía, 1997) (4).

En segundo lugar, porque el periodo de vigencia de esta ley fue muy corto, siendo reemplazada algunos meses después por la Ley Orgánica 8/2000, que entró en vigor en enero de 2001. Esta nueva ley reestableció la expulsión (5) como sanción para los inmigrantes irregulares, al tiempo que les denegaba los derechos de reunión, huelga e incluso el de sindicación (Barreiro, 2001). Así lo expresó un periodista Italiano: 'El Gobierno del Presidente Aznar ha declarado la guerra a los inmigrantes' (Lannes, 2001: 16). La muestra más dramática de esta nueva etapa más restrictiva es el proyecto SIVE Revista de Española de Investigación Criminólogica 
(Servicio Integrado de Vigilancia del Estrecho), por el que se han instalado a lo largo de los $900 \mathrm{~km}$ de la costa de Andalucía una sofisticada tecnología militar de vigilancia. Esta obra es conocida como 'el Muro de Aznar' (Lannes, 2001: 16). A pesar de este rápido retorno a una política de expulsión y repatriación, el breve periodo de vigencia de la anterior ley, que dejó en suspenso las expulsiones, resulta muy interesante ya que pone de manifiesto la contradicción existente en el eje central de la política migratoria: inmigrantes irregulares son simultáneamente criminalizados y consentidos con reticencias, marginados pero a la vez piezas clave de las economías post Fordistas. La ley de extranjería 4/2000 mostró las contradicciones del sistema con demasiada sinceridad, y por ello no pudo sobrevivir por mucho tiempo al apasionado debate sobre la inmigración.

Las distintas dimensiones que componen la situación de ilegalidad de un inmigrante quedan de alguna forma reducidas al llegar a ser reconocido como cuasi-miembro de la comunidad (6). Debido a que los inmigrantes irregulares son raramente expulsados, incluso después de la reforma, y a que se ha extendido la defensa de ciertos derechos civiles de este colectivo, la dimensión de ilegalidad se reduce al ámbito laboral, donde sí es una población claramente marcada por esa diferencia. Mientras aumenta el reconocimiento de que los trabajadores inmigrantes son más o menos residentes habituales, su ilegalidad se mantiene de hecho en la esfera de sus relaciones laborales, donde están sometidos a duras penalizaciones tales como salarios desiguales, ausencia de derechos laborales, etc, todas ellas asociadas con el ámbito de la economía informal y sumergida al que son relegados. No se puede negar, desde luego, que estas desventajas laborales puedan llevar a algunos inmigrantes a cometer actividades delictivas. Lo que quiero decir aquí es que para los inmigrantes cuyo 'único delito' es su estatus ilegal ('su irregularidad'), es en su actividad laboral donde son más severamente penalizados, y por ende criminalizados. Con el presente argumento no quiero minimizar los efectos que la ilegalidad de los inmigrantes tiene fuera de su lugar de trabajo, ni sugerir que esa aceptación ambivalente les hace de alguna manera menos 'extraños'. Aunque la ejecución de las expulsiones es relativamente infrecuente en España, el miedo a la detección es agudo, y afecta a todas las esferas de la vida. La ley de extranjería prevé la posibilidad de ingresar cautelarmente a un inmigrante en un centro de detención durante el tiempo necesario para la sustanciación del procedimiento administrativo de expulsión, con un máximo de 40 días. Un informe reciente del Colegio de Abogados de Madrid (citado en Escudero, 1999; 20) revela que en esos centros de detención se observan menos derechos legales, dispone de menos servicios sociales y sanitarios que en los centros penitenciarios españoles, son gestionados con gran discrecionalidad burocrática, y casi seguro son inconstitucionales (7).

No hay estadísticas disponibles sobre el número de inmigrantes que pasan por estos centros de detención, pero según SOS Racismo las detenciones en estos centros son suficientemente comunes como para representar una amenaza con efectos muy destructivos sobre los inmigrantes (SOS Racismo, 1996). El testimonio de un inmigrante argelino fue: 'Nuestra vida es una continua huida de la policía, ya que no tenemos papeles. Vivimos con ansiedad permanente. Parece que tenemos un cartel en la frente que dice "soy ilegal"" (citado en Dahiri y Acosta, 1994: 119). Ese constante temor consolida la situación de vulnerabilidad que el inmigrante ya tiene en el mercado laboral. Un experto (Pumares, 1996: 76) relata la entrevista que tuvo con una mujer marroquí que trabajaba en el servicio doméstico. Durante la misma reconoció haber rechazado un empleo mejor pagado porque su empleadora la amenazó con denunciarla a la policía si le dejaba.

Revista de Española de Investigación Criminólogica 
En Outlaws in the Promised Land, Cockcroft (1986) cuenta la historia de la inmigración de mexicanos a los EEUU y muestra el papel que juega esta inmigración en la economía de los EEUU. Cita (1986: 130) un artículo del Wall Street Journal en el que se comenta la importancia de la 'actual ola de inmigrantes del hemisferio occidental' a la hora de compensar el declive de los beneficios en los años setenta. 'Puede ser que los ilegales estén aportando el margen de supervivencia necesario para sectores enteros de la economía'. Diez años después, el Wall Street Journal (citado en Cockroft, 1986: 130) lucía como titular 'Inmigrantes ilegales forman la columna vertebral de la economía en los estados del Suroeste - fabrican las piezas de los ordenadores, envasan las píldoras para la artritis, cocinan, limpian - prisioneros en barracones'. Cockcroft revela con ello los abusos y la denegación de derechos civiles en unos centros de detención que son en realidad verdaderas cárceles. Así detalla el castigo económico que sufren estos 'prisioneros en barracones' y los benéficos económicos que al mismo tiempo producen.

La dinámica es muy parecida a la española. Los inmigrantes son bienvenidos por la flexibilidad que aportan a la economía, pero la ley y las políticas aseguran que una parte importante de esos inmigrantes del Tercer Mundo puedan ser definidos en un momento dado como ilegales. De Lucas resume el efecto de esta amplia ilegalidad, incluyendo la 'existencia de relaciones laborales, a menudo clandestinas, que implica que marroquíes, guineanos, etc. vivan - en relación con sus medios de subsistencia, la vivienda, salud y ingresos- en una situación muy cercana a la esclavitud' (1994: 85).

\section{Conclusión}

Aunque he hablado a lo largo de este trabajo de 'inmigrantes' e 'inmigrantes ilegales', hay que recordar que en España estos términos sólo se refieren a las personas que proceden de países del llamado Tercer Mundo, y que trabajan en empleos no-cualificados en los márgenes de la economía, aunque en realidad se constituye en el eje central del sistema post-Fordista. Thranhardt y Miles comentan los efectos de la actual globalización: 'Habrá un único club de países ricos' (1995: 5), con ciudadanos de los países pobres relegados a los márgenes. Y 'debajo, formando las prácticas de exclusión están... los conceptos racistas de "los otros" (1995: 3). En este nuevo orden económico y social, las implicaciones son más complicadas que las meramente representadas por las dicotomías inmigrante /ciudadano o 'alguien de fuera' / miembro. Legal, política e ideológicamente la comunidad se ha extendido más allá del Estado-nación para incluir - en el caso de España - el resto de Europa Occidental o la Comunidad Europea. Así, no todo extranjero viene desde 'fuera de la comunidad' y no todo extranjero es 'extraño' u 'otro' Y cada vez más, la decisión de quién es el verdadero 'extraño' y quién debe ser controlado, se adopta sobre la base de su ubicación en la economía global, y no sobre el concepto técnico de inmigrante. La raza juega un papel central en esta exclusión, pero no es el criterio definitivo, ni podría serlo, ya que la raza en sí es una construcción social. Igual que los trabajadores españoles e italianos en Alemania, Francia y Suiza en los años cincuenta y sesenta fueron considerados racial y culturalmente inferiores, para convertirse en 'blancos' y miembros de la Comunidad Europea apenas 30 años después, en el caso de los trabajadores marginados del Magreb y ciertos países suramericanos en España, raza, exclusión y función económica forman una única pieza.

Finalmente, el hecho que la ley de extranjería española produzca y reproduzca ilegalidad y así criminalice a los inmigrantes, a la vez que consiente implícitamente su Revista de Española de Investigación Criminólogica 
presencia, capta dramáticamente la contradicción entre el papel central que juega el inmigrante en la economía post Fordistas y su exclusión de la comunidad nacional.

Hace medio siglo, Marshall (1959) escribió sobre clases sociales y ciudadanía en Inglaterra, y argumentaba que el siglo XX había visto una expansión de derechos civiles, políticos y sociales de los miembros de pleno derecho de la comunidad política. Los críticos de Marshall han indicado que su definición de ciudadanía como un estatus fijo, otorgado a todos los miembros de una comunidad nacional, no es muy acertada. Como dice Yuval-Davis, Marshall suponía que la colectividad - y ser miembro de ella - es algo fijo y estático, en lugar de ser una construcción ideológico y material, cuyas fronteras, estructuras y normas son el resultado de procesos continuos de luchas y negociaciones, o de dinámicas sociales más generales (1990: 3 ).

El trato dispensado a los inmigrantes ilegales en España muestra nítidamente la fluidez y las contradicciones que conlleva ser 'miembro' de la comunidad. Etiquetados como ilegales, aunque raras veces expulsados, los inmigrantes ilegales son a la vez miembros y no-miembros. No es que la mera dicotomía miembro/ 'alguien de fuera' no sea claramente adecuada, sino que su boleto de entrada (limitada) como miembro en la comunidad nacional es precisamente la criminalización del inmigrante en el mercado laboral, al constituirse en un antídoto valioso contra las rigideces económicas. En otras palabras, el mercado laboral es el lugar donde son más criminalizados y penalizados, al mismo tiempo que es el lugar donde los inmigrantes ilegales son más apreciados. Esto sin duda contribuye en parte a la 'descriminalización' de facto de los inmigrantes, al ser considerados miembros parciales de la comunicad.

En su libro pionero sobre Immigrant workers and class structure in Western Europe publicado hace 30 años, Castles y Kosak comentaron que 'la inmigración de trabajadores manuales hacia Europa del Oeste es parecida a una colonización a la inversa' (1973: 481). Esta colonización a la inversa, y el existente aparato legal que lo hace posible, es tan complicada como la versión original de la colonización. Y como en la versión original, son muchas las contradicciones legales. Desenredar estas contradicciones, como he intentado hacer aquí, centrándome en los conceptos de criminalización y castigo, puede ayudar a empezar a comprender la lógica de esta colonización a la inversa.

\section{Notas}

1. También puede ser, como sugieran Sánchez Yllera (1990) y Melossi (2000a), que las circunstancias sociales y económicas pueden crear espacios de actividad criminal, como tráfico de drogas y prostitución, donde algunos inmigrantes pueden predominar. Aunque esto puede contribuir a que los niveles de encarcelación sean más altos, ni Sánchez Yllera ni Melossi defienden que sea un mayor nivel de actividad delictiva lo que puede explicar las dramáticas diferencias entre el número de inmigrantes detenidos y encarcelados en comparación con los autóctonos.

2. La cifra es comparable a la de otros países de Europa occidental. En Italia, aproximadamente el $15 \%$ de los presos son extranjeros, y en algunas de las grandes cárceles del norte llegan a ser casi la mitad de los presos (Melossi, 2000a: 158, 2000b). En Alemania, donde el porcentaje de extranjeros entre la población en general es algo más alto, los inmigrantes son alrededor del 35\% de los presos (Barbagli, 1998: 27).

Revista de Española de Investigación Criminólogica 
3. Hay que recordar, como comenta Pugliese, que aunque los inmigrantes pueden ser encontrados incluso en países con altos niveles de paro (como el caso de España), ellos tienden a concentrase en los regiones con menor paro, como las zonas industriales del centro y del noreste.

4. El número de expulsiones incoadas y ejecutadas es información oficialmente clasificada. Debido a que la expulsión es competencia de la Policía Nacional, se considera que son datos relacionados con la seguridad, y no están disponibles para el público. Obtuve estos datos a través de correspondencia privada con el departamento de Justicia y después de tener que asegurar repetidas veces que la información sería destinada exclusivamente al uso académico. Se me ocurrió, viendo los números tan bajos, que pueden existir razones políticas para no querer publicitarlos.

5. El coste de la repatriación probablemente sea un factor explicativo del escaso número de inmigrantes que llegan a ser expulsados. Se estima que sólo el precio de los billetes de avión para repatriar a los ecuatorianos es de aproximadamente 885 millones de pesetas, más de 6 millones de dólares (Lannes, 2001: 16).

6. En Italia este ambiguo estatus se refleja en la nueva categoría conocida como 'extranjeros temporalmente presentes' en el territorio, que son los inmigrantes irregulares que pueden recibir cuidados médicos de urgencia.

7. Un debate parecido existe en relación con el estatus constitucional de los centros de detención en Italia, donde frecuentemente se argumenta que las condiciones de estos centros son peores que las de las cárceles (Gullo, 2001: 59-60).

\section{BIBLIOGRAFÍA}

$A B C$ (2002) 'España Acoge a Más de un Millón de Inmigrantes Legales,' Abril 17,2002.

Amnesty International (2002) 'Spain: Crisis of Identity, Race-Related Torture and Ill-Treatment by State Agents,' Abril

16, 2002, www.amnesty.org

Barbagli, Marzio (1998) Immigrazione e criminalita in Italia. Bologna: Il Mulino.

Barreiro, Belén (2001) 'Una democrazia in cerca di conferme', Il Mulino L(395):

408-17.

Behdad, Ali (1997) 'Nationalism and immigration to the United States', Diaspora 6(2):155-78.

Boletín Oficial del Estado (1985) Número 158, 3 Julio.

Boletín Oficial del Estado (2000a) 'Ley Orgánica 4/2000, de 11 de enero, sobre Derechos y Libertades de los Extranjeros en España y su Integración Social', Madrid.

Boletín Oficial del Estado (2000b) 'Ley Orgánica 8/2000, de 22 de diciembre, de reforma de la Ley de Extranjería', Madrid.

Bourdieu, Pierre (1991) 'Preface', en Sayad Abdelmalek, L'immigration: Ou les paradoxes de l'alterité, pp. 7-9.

Bruselas: De Boeck-Wesmael.

Brubaker, Rogers (1992) Citizenship and nationhood in France and Germany. Cambridge, MA: Harvard University

Press.

Bustamante, Jorge (1978) 'Commodity-migrants: Structural analysis of Mexican immigration to the U.S.', en S. Ross

(ed.) Views across the border, pp. 183-203. Albuquerque, New Mexico: University of New Mexico Press.

Calavita, Kitty (1992) Inside the state: The Bracero Program, immigration, and the INS. New York: Routledge.

Calavita, Kitty (1998) 'Immigration, law, and marginalization in a global economy: Notes from Spain', Law and Society

Review 32(3): 529-66.

Castles, Stephen y Godula Kosack (1973) Immigrant workers and class structure in Western Europe. London: Oxford University Press.

Cockcroft, James D. (1986) Outlaws in the Promised Land: Mexican immigrant workers and America's future. New

York: Grove Press.

Revista de Española de Investigación Criminólogica

REIC NI-03-04 http://www.criminologia.net/revista

ISSN 1696-9219 
Colectivo Ioe (1992) Los trabajadores extranjeros en España: Informe para el Instituto Sindical de Estudios. Madrid:

Colectivo Ioe.

Colectivo Vírico (1994) Extranjeros en el paraíso. Barcelona: Edicions La Lletra SCCL.

Comisión Interministerial de Extranjería (1995) Anuario estadístico de extranjería. Madrid: Secretaria General Técnica.

Ministerio de Justicia e Interior.

Cornelius, Wayne A., Philip L. Martin y James F. Hollifield, eds (1994) Controlling immigration: A global perspective.

Stanford, CA: Stanford University Press.

Dahiri, Mohamed y Diamantino Garcia Acosta (1994) 'La inmigracion en España', en el Colectivo Vírico (eds)

Extranjeros en el paraíso, pp. 115-22. Barcelona: Edicions La Lletra SCCL.

De Lucas, Javier (1994) Europa.¿ Convivir con la diferencia? Racismo, nacionalismo y derechos de las minorías.

Madrid: Editorial Tecnos.

De Lucas, Javier (1996) Puertas que se cierran: Europa como fortaleza. Barcelona: Icaria.

Escudero, Ana (1999) 'Los abogados de Madrid dicen que en los centros de extranjeros hay menos garantías que en prisión’, El País 15 Junio, p. 20.

Generalitat de Catalunya (1995) Entre el sud i el nord: Els treballadors immigrants estrangers a Catalunya. Barcelona:

Generalitat de Catalunya.

Generalitat de Catalunya (2002) 'Dades de la Immigracio a Catalunya,' documento inédito.

Gonzalez-Anleo, J. (1993) 'El poblado Marroqui de Manuel Garrido: Una aproximación sociológica', Sociedad y Utopia:

Revista de Ciencias Sociales 1 (Marzo): 171-92.

Gullo, Tano (2001) 'Se E’ questo il modo di accoglierli', La Repubblica 20 Julio, pp. 59-60.

Ingwerson, Marshall (1993) 'Workers' brave new job frontiers', The Christian Science Monitor 24 Marzo, pp. 9, 12.

Izquierdo, Antonio (1996) La inmigración inesperada. Madrid: Editorial Trotta.

Jabardo, Mercedes (1995) 'Etnicidad y mercado de trabajo: Inmigración Africana en la agricultura', Perspectiva Social

36: 81-95.

Lannes, Gianni (2001) 'Il muro di aznar contro i clandestini', L'Unità 22 Julio, p. 16.

Lipietz, Alain (1985) The enchanted world: Inflation, credit and the world crisis. London: Verso.

Lipietz, Alain (1987) Mirages and miracles: The global crisis of Fordism. London: Verso.

Malgesini, Gabriela (1994) 'Dilemas de la movilidad: Inmigración y refugiados en España y la CE', en el Colectivo

Vírico (eds) Extranjeros en el paraíso, pp. 11-26. Barcelona: Edicions La Lletra SCCL.

Marshall, F. Ray (1978) 'Economic factors influencing the international migration of workers', en S. Ross (ed.) Views across the border, pp. 163-80. Albuquerque: University of New Mexico Press.

Marshall, T.H. (1950) Citizenship and social class and other essays. Cambridge: Cambridge University Press.

Mazuelos, Almudena (1997) 'Tres de cada cuatro contratos firmados en el 96 duraron menos de tres meses', $Y a 24$ Enero, p. 17.

Melossi, Dario (1999) 'Immigrazione, pluralismo culturale e sicurezza: Una ricerca in Emilia-Romagna', Dei Delitti e

Delle Pene 6(3): 38-75.

Melossi, Dario (2000a) 'The Other in the New Europe: Migrations, deviance, social control', en P. Green y A. Rutherford (eds) Criminal policy in transition, pp. 151-66. Oxford: Hart Publishing.

Melossi, Dario (2000b) 'Alla ricerca di una "vita tranquilla”: Immigrazione, criminalità e Italian way of life', Quaderni di Citta Sicure 6(21): 17-69.

Mercado (1992) 'Miedo a lo desconocido', 24 Febrero, p. 27.

Ministerio de Asuntos Sociales. Dirección General de Migraciones (1995) Plan para la integración social de los inmigrantes. Madrid: Ministerio de Asuntos Sociales.

Ministerio del Interior (1996) Normativa básica de extranjería. Madrid: Ministerio del Interior, Secretaria General

Técnica.

Ministerio del Interior (2001) Anuario Estadístico de Extranjería. Madrid: Ministerio del Interior, Secretaria General

Técnica.

Ministerio del Interior. Dirección General de Instituciones Penitenciarios (2001) 'Datos estadísticos de la población reclusa total nacional', Febrero Madrid: Ministerio del Interior.

Ministerio de Trabajo y Asuntos Sociales (1997) Boletín de Estadísticas Laborales, Numero 143 (Abril). Madrid:

Secretaria General Técnica, Ministerio de Trabajo y Asuntos Sociales.

Observatorio Permanente de la Inmigración (1999) Indicadores de la inmigración y e lasilo en España, Numero 5, Abril.

Piore, Michael y Charles Sabel (1984) The second industrial divide. New York: Basic Books.

Pugliese, Enrico (1995) 'New international migrations and the "European fortress", en C. Hadjimichalis y D. Sadler (eds) Europe at the margins: New mosaics of inequality, pp. 51-68. New York: John Wiley \& Sons Ltd.

Pumares, Pablo (1996) La integración de los inmigrantes Marroquies: Familias Marroquíes en la comunidad de Madrid. Barcelona: Fundación 'la Caixa'.

Ramirez Goicoechea, Eugenia (1996) Inmigrantes en España: Vidas y experiencias.Madrid: Centro de Investigaciones Sociológicas.

Roquero, Esperanza (1996) ‘Asalariados Africanos trabajando bajo plástico’, Sociología del Trabajo 28 (Otoño): 3-23.

Sanchez Yllera, Ignacio (1990) 'Extranjeros en prisión: Doble condena', Jueces para la Democracia 10(Septiembre): 6570.

Revista de Española de Investigación Criminólogica

REIC NI-03-04 http://www.criminologia.net/revista

ISSN 1696-9219 
Santos, Lidia (1993) 'Elementos jurídicos de la integración de los extranjeros’, en G. Tapinos (ed.) Inmigración e integración en Europa, pp. 91-125. Barcelona: Itinera Libros.

Sayad, Abdelmalek (1996) 'La doppia pena del migrante. Riflessioni sul pensiero di stato', Aut Aut 275: 8-16.

Sayer, Andrew y Richard Walker (1992) The new social economy: Reworking the division of labor. Cambridge:

Blackwell.

Simmel, Georg (1950) The sociology of Georg Simmel. Trans., ed. Y con una introducción de Kurt H. Wolff. New York: Free Press.

Simon, Jonathan (1993) Poor discipline: Parole and the social control of the underclass, 1890-1990. Chicago, IL: The University of Chicago Press.

Sole, Carlota (1995) Discriminación racial en el mercado de trabajo. Madrid: Consejo Económico y Social.

SOS Racismo (1996) Informe anual sobre el racismo en el estado Español. Barcelona: SOS Racismo.

Thranhardt, Dietrich y Robert Miles (1995) 'Introduction', en R. Miles y D. Thranhardt (eds) Migration and European integration: The dynamics of inclusion and exclusion, pp. 1-12. London: Pinter Publishers.

Valls, Andreu Domingo, Jaume Clapes Estrada y Maria Prats Ferret (1995) Condicions de vida de la poblacio d'origen Africa i Llatinoamerica a la regio metropolitana de Barcelona: Una aproximacio qualitativa. Barcelona: Diputacio de Barcelona.

Young, Alison (1996) Imagining crime: Textual outlaws and criminal conversations. London: Sage Publications. Yuval-Davis, Nira (1990) 'Women, the state, and ethnic processes', ponencia presentada a la Conference on Racism and Migration in Europe, Hamburg, Germany, 27-30 September.

\section{LA AUTORA}

KITTY CALAVITA es profesora de Criminología, Derecho y Sociedad en la Universidad de Irving, California. Escribe sobre políticas de inmigración y otros temas relacionados con el derecho, el poder y las ideologías. Sus investigaciones actuales versan sobre las políticas migratorias en Europa y explora las tensiones asociados a la construcción social de alteridad relacionada con la inmigración.

Revista de Española de Investigación Criminólogica

REIC NI-03-04

http://www.criminologia.net/revista

ISSN 1696-9219

https://doi.org/10.46381/reic.v2i0.16 